Department of Social Systems and Management

\author{
Discussion Paper Series
}

No. 1245

Quantitative Evaluation of Nation Stability

by

Takao Tsuneyoshi, Akihiro Hashimoto and Shoko Haneda

September 2009

UNIVERSITY OF TSUKUBA

Tsukuba, Ibaraki 305-8573

JAPAN 


\title{
Quantitative Evaluation of Nation Stability
}

\author{
Takao Tsuneyoshi ${ }^{\mathrm{a},{ }^{*}}$, Akihiro Hashimoto ${ }^{\mathrm{b}, \dagger}$, Shoko Haneda ${ }^{\mathrm{c}, *}$ \\ ${ }^{a}$ Doctoral Program in Social Systems and Management, University of Tsukuba, \\ Tsukuba, Ibaraki 305-8573, Japan \\ ${ }^{\mathrm{b}}$ Department of Social Systems and Management, University of Tsukuba, \\ Tsukuba, Ibaraki 305-8573, Japan \\ ${ }^{\mathrm{c}}$ Faculty of Business Administration, Komazawa University, \\ Komazawa, Setagaya, Tokyo 154-8525, Japan
}

\begin{abstract}
This paper presents a Data Envelopment Analysis/Malmquist Index (DEA/MI) analysis for measuring changes in nation stability, which is defined as the state of a country's social and economic system as measured by multiple evaluation indicators. Applying the DEA to the panel data for 97 countries during 1981-2004, we evaluate nation stability quantitatively, and observe its transitions. This analysis includes a unified country (Germany) and split countries (former Soviet Union, Czechoslovakia, and Yugoslavia). Using the novel DEA/Cumulative MI application proposed in this study, we demonstrate shifts in stability before/after the unification or split. Our analysis shows that the stability gap between the most stable countries and other countries expanded after the end of the cold war, until 2004. The stability of split countries fell typically by 50\% or more, so they were extremely unstable before the split. The use of the lower-bound DEA together with the ordinary DEA enables a country's stability to be evaluated in terms of both its negative and positive aspects.
\end{abstract}

Keywords: Nation stability; Indicators of country stability; Merger and split; Data envelopment analysis; Malmquist index; Unified country; Split country

\section{Introduction}

Various degrees of political, economic, and social stability exist in individual countries. People suffer from problems that may have originated in their own country or come from abroad. Naturally, problems and instability have a negative influence on the diplomatic relations between countries, including their political and economic aspects. Therefore we arbitrarily judge whether

\footnotetext{
*Corresponding author. E-mail: ttsuneyoshi@sk.tsukuba.ac.jp

"E-mail: hashimot@ sk.tsukuba.ac.jp

*E-mail: shaneda@komazawa-u.ac.jp
} 
a country is stable or unstable by synthetically treating various problems that surround that particular country. However, this evaluation must be fair-minded and objective because it is related to private/public decision-making in international activities. Transnational threats emerging from a country that terrify adjacent countries and even those further afield, need to be considered in any notion of stability. In this study, we deal with the way in which a country's stability affects both domestic and foreign decision-making in various fields. We refer to this overall concept as "nation stability."

This paper quantitatively measures the nation stability of 97 countries (see Table A.1) and examines how their nation stability changed during the period 1981-2004. Each country's stability is deeply related to the quality-of-life (QOL) of its citizenry. It is important to evaluate nation stability because it tends to play a very large role in determining the QOL of an unstable country. In the case of international relations, researchers have analyzed bilateral relationships by using scored event data (Goldstein 1992; Bond et al. 2003), the impact of terrorism or warfare (Nitsch and Schumacher 2004), and the effect of all types of conflict (Blomberg and Hess 2006) on international trade. Mirza and Verdier (2008) surveyed the recent economic literature on terrorism, and discussed the increase in security costs related to terrorism prevention. Their paper, however, does not employ a direct measure of nation stability. Measuring nation stability is significant for a clear understanding of both individual countries and international relations. Rotberg $(2003$, 2004) discussed failed states qualitatively, but nation stability has never been analyzed quantitatively. One critical reason for this lack is that nation stability is difficult to define universally, because its form is intangible and its evaluation is never completely objective. With these limitations in mind, but with a firm recognition of the external influences that each country exerts on the rest of the world, we here try to measure nation stability.

To establish a framework for nation stability, we begin by defining stability in terms of the state of a social and economic system (influenced by both internal and external factors), as measured by multiple evaluation indicators. When multiple indicators are employed, their weighted sum is generally taken as an integrated measure of all indicators. However, it is difficult not only to define such a weighting a priori, but also to interpret it when deriving through a particular multivariate technique. We thus employ a Data Envelopment Analysis (DEA) (e.g., Cooper et al. 2000), which is a well-known and respected methodology that can circumvent dealing with fixed weights. We can thus establish a flexibly defined weighting system across the decision-making units (DMUs) that are being evaluated.

DEA is a mathematical programming technique for measuring the relative efficiency of DMUs that have multiple inputs and outputs. Specifically, for the current research, we replace the inputs with negative indicators (the smaller the value, the better), and the outputs with positive indicators (the greater the value, the better), thus enabling an evaluation of each DMU's nation stability.

In this respect, we note that inputs produce outputs, but negative indicators do not, under any circumstances, produce positive indicators. We thus view our effort as different from a "standard" DEA production efficiency analysis. Our approach was originally proposed by Hashimoto and Ishikawa (1993), and then discussed/applied in Hashimoto (1993, 1996, 1997), Hashimoto and Kodama (1997), Zhu (2001), Reisman et al. (2002), Murias et al. (2006, 2008), Hashimoto et al. (2009), and Somarriba and Pena (2009). We now examine transitions in nation stability using a DEA/Malmquist Index (DEA/MI) approach (e.g., Färe et al. 1994; Thanassoulis 2001), which is actually a DEA time series that accounts for a shifting frontier. This approach enables measurement of the ratio of DEA efficiencies in two different time periods that have dynamic (shifting) efficiency frontiers. Given the inputs and outputs identified in this paper, we can then quantitatively evaluate changes in nation stability.

Methodologically, we propose a new application of DEA/MI to cases of DMU merger and splitting. Specifically, our analysis includes unified Germany and the successor countries of the split Soviet Union, Czechoslovakia, and Yugoslavia. It should be noted that the traditional method of applying DEA/MI cannot explain the changes in nation stability across the boundary of a serious juncture (i.e., before/after the year of unification or splitting). In addition to analyzing 
each country's shifts in nation stability, we demonstrate graphic shifts of the unified/split countries taken together. We thus apply DEA/MI to DMU mergers and splits. Indicator panel data for 97 countries (including Taiwan) during 1981-2004 (excluding only 1993) are analyzed, in order to discuss change in each country's nation stability across the entire study period.

\section{Nation stability}

\subsection{Notion of nation stability}

Nation stability in this study is a general concept that is defined in such a way as to be useful to people engaged in diverse international activities, such as political, economic, and cultural exchange. Although each country's vulnerability is already recognized as an internal steadiness that incorporates influences from outside, nation stability has a more comprehensive meaning that impacts international organizations, foreign relations, and foreign investment. In addition to domestic influences, nation stability accounts for influences that come from abroad, and also influences that manifest abroad. Each country's state of stability is generally divided into a social aspect and an economic aspect. The economic phase needs to be analyzed independently from the state of society, because the national economy has significance both at home and abroad. Let us now take a look at failed nation-states, in order to differentiate the concrete economic and social states for evaluating overall nation stability.

\subsection{Study of failed states}

Rotberg $(2003,2004)$ established criteria by examining contemporary cases of nation-state failure due to generic weakness or apparent distress, and the consequent collapse from failure. His analysis involved a gradual scale from weak state to failing state to failed state, according to the likelihood of failure. He defined a collapsed state as the extreme end of the spectrum, beyond "failed state." His criterion for this classification is the country's ability to deliver political goods to persons living within its designated borders. Rotberg utilized a hierarchy of political goods, with security ranked at the top, above political freedom (civil liberties), medical care, education, and infrastructure maintenance, all of which he placed at a subordinate level. However, these political goods are intangible and hard to quantify.

Rotberg further classified nation-states into two groups: strong states and weak states. The former countries unequivocally control their territories and deliver a full range of high-quality political goods to their citizens. In such a country, public safety and political liberty are both well maintained, education and medical care are solid, and GDP per capita is high, with steady economic growth. The latter countries are inherently weak because of geographical, physical, or economic constraints. They experience many serious problems, such as internal antagonisms, mismanagement, greed, despotism, external attacks, high crime rates, communal tensions, the deterioration of the services of schools and hospitals, and deteriorated physical infrastructure. Naturally their economic growth and business climate tend to stagnate or worsen. Rotberg thus elucidated the conditions of nation-states according to both the quality and the quantity of the political goods that they provide to their people.

A country's weakness or strength, as described by Rotberg, is identical with our notion of nation stability, except that he omits the external influences that impact foreign countries. In view of the significance of such outward influences, we define nation stability in broader terms.

\subsection{Framework for evaluating nation stability}


Nation stability embraces both internal and external stability. The former corresponds to the domestic state of being, namely the national affairs that depend on government operations. The latter involves matters in which the country in question is a significant constituent of an international community.

In Figure 1, we present our comprehensive framework of nation stability, in which a country's state is described in terms of four aspects: internal economy, external economy, internal society, and external society. Rotberg's notion of stability is conceptually equivalent to the white part (designated as portion i), which, roughly speaking, occupies three-fourths of a country's stability. The missing fourth is the outward influence of external aspects exerted on other countries. We think that nation stability must include international threats and contributions that a country sends abroad (designated as portion ii). In other words, nation stability includes mutual international-influence: both halves of each external aspect, thus accommodating influences to and from the world at large. So we define an entire country (portion iii) by adding the gray part (portion ii: influences that flow outward) to Rotberg's notion. In Table 1, we illustrate each of the four aspects with representative examples of the phenomena. The metric in this paper is thus defined in terms of stability in the four aspects of social and economic systems.

\section{$3 \quad$ Methodology}

Since DEA/MI is employed as the analytic method of choice in the current study, we now briefly discuss its underlying principles, following the explanation given by Hashimoto et al. (2009).

\subsection{DEA and negative DEA}

DEA was first presented in a seminal article by Charnes, Cooper, and Rhodes (CCR, 1978). Mathematically, the CCR model, in its weak efficiency and ratio form, generates an efficiency score for decision-making unit(s) (DMU) of interest $j_{0}, g_{j_{0}}\left(0 \leq g_{j_{0}} \leq 1\right)$. It is formulated as the following fractional program (FP):

$$
\begin{array}{ll}
\text { Maximize } & g_{j_{0}}=\frac{\sum_{r=1}^{t} u_{r} y_{r j_{0}}}{\sum_{i=1}^{m} v_{i} x_{i j_{0}}} \\
\text { subject to } & \frac{\sum_{r=1}^{t} u_{r} y_{r j}}{\sum_{i=1}^{m} v_{i} x_{i j}} \leq 1, j=1, \ldots, n \\
& u_{r}, v_{i} \geq 0, r=1, \ldots, t, i=1, \ldots, m,
\end{array}
$$

where: $n=$ number of DMUs, $y_{r j}=$ output $r$ from DMU $j, u_{r}=$ weight assigned to output $r, t=$ number of outputs, $x_{i j}=$ input $i$ from DMU $j, v_{i}=$ weight assigned to input $i$, and $m=$ number of inputs.

We can generate DEA scores $g_{j_{0}}$ for all DMUs by solving (1) $n$ times, setting each DMU as the target DMU $j_{0}$ in turn. Here, DMUs $j_{0}$ with the optimum $g_{j_{0}}^{*}=1$ are judged DEA efficient, while those with $g_{j_{0}}^{*}<1$ are defined as DEA inefficient.

Using (1), DEA judges any DMU producing more outputs with fewer inputs relatively efficient (DEA efficient). In our nation stability analysis, where the inputs and outputs are replaced, respectively, by negative and positive evaluation indicators, any DMU having greater positive indicators and smaller negative indicators is judged to be "relatively stable." Thus, the score $g_{j_{0}}$ in our analysis is a metric of nation stability. We can accept such a metric under the circumstances in which nation stability has been a concept without a consensus definition. DMUs $j_{0}$ with $g_{j_{0}}^{*}=1$ might thus be judged to have a "best stability," while those with 
$g_{j_{0}}^{*}<1$ will simply possess a "not-best stability." Further, since the DEA model in a nation stability context does not measure efficiency, we need not take the DMU scale (as measured by model inputs or outputs) into consideration in computing the nation stability ratio $g_{j_{0}}$. Thus, we employ the CCR model rather than that of Banker, Charnes, and Cooper (BCC, 1984).

As the maximization of (1) shows, ordinary DEA is an upper-bound evaluation focusing on each DMU's superiority. To evaluate nation stability in terms of both "good" and "bad" respects, we introduce the following DEA variation, "negative DEA" as a lower-bound evaluation (Yamada et al. 1994; Doyle et al. 1995). In contrast with (1), the model, in its weak efficiency and ratio form, is:

$$
\begin{array}{cl}
\text { Minimize } & f_{j_{0}}=\frac{\sum_{r=1}^{t} u_{r} y_{r j_{0}}}{\sum_{i=1}^{m} v_{i} x_{i j_{0}}} \\
\text { subject to } & \frac{\sum_{r=1}^{t} u_{r} y_{r j}}{\sum_{i=1}^{m} v_{i} x_{i j}} \geq 1, j=1, \ldots, n \\
& u_{r}, v_{i} \geq 0, r=1, \ldots, t, i=1, \ldots, m .
\end{array}
$$

Here, the negative-DEA score of target DMU $j_{0}, f_{j_{0}} \geq 1$, and DMUs $j_{0}$ with $f_{j_{0}}^{*}=1$, are on the DEA rear boundary (negative-DEA frontier). In our analysis, any DMU having smaller positive and greater negative social indicators is judged "relatively bad." Thus, DMUs $j_{0}$ with $f_{j_{0}}^{*}=1$ should be judged as having "DEA worst instability," while DMUs $j_{0}$ with $f_{j_{0}}^{*}>1$ would have "DEA not-worst instability."

\subsection{DEA/MI analysis}

DEA/MI analysis measures the Malmquist (productivity) index (Malmquist 1953) within a DEA framework. Figure 2 presents a single input and output DEA case in which DMU $j_{0}$ was at point A in period $\alpha$, and line OCD represents the CCR DEA frontier. The input-oriented efficiency of DMU $j_{0}$ is then measured by $P C / P A(<1$, DEA inefficient). When point $\mathrm{A}$ is on the frontier, its score is 1 (DEA efficient). Suppose that, in period $\beta(\beta>\alpha)$, DMU $j_{0}$ has moved to point $\mathrm{B}$, and that the frontier itself has also shifted, to line OEF. The efficiency change in DMU $j_{0}$ can be measured by the ratio of its DEA score in period $\beta$ to that in period $\alpha$; however, the frontier has shifted, so that we must compute the geometric mean of the ratios for the two frontiers in those same periods. This is the DEA (CCR input-oriented)/Malmquist index for DMU $j_{0}$ between periods $\alpha$ and $\beta$, given in (3):

$$
M I_{j_{0}}[\alpha, \beta] \equiv\left(\frac{Q D / Q B}{P C / P A} \cdot \frac{Q F / Q B}{P E / P A}\right)^{1 / 2}
$$

Here $M I>1$ implies a gain in DEA efficiency by DMU $j_{0}$ from period $\alpha$ to $\beta$, while $M I=1$ and $M I<1$ imply stasis and loss, respectively.

Transforming (3), the Malmquist index can be decomposed into two components, as follows:

$$
\begin{aligned}
M I_{j_{0}}[\alpha, \beta] & =\frac{Q F / Q B}{P C / P A} \times\left(\frac{P C / P A}{P E / P A} \cdot \frac{Q D / Q B}{Q F / Q B}\right)^{1 / 2} \\
& =C U_{j_{0}}[\alpha, \beta] \times F S_{j_{0}}[\alpha, \beta] .
\end{aligned}
$$

As the first term on the right hand side (RHS) of (4) shows, CU expresses the Catch-Up in- 
dex. That is, $C U>1$ suggests that DMU $j_{0}$ has moved closer to the period $\beta$ frontier than to that for period $\alpha . C U=1$ or $C U<1$ thus applies when an identical or greater distance, respectively, is involved. We define the second term on the RHS of (4) as the Frontier Shift (FS) index, where $F S>1$ means a gain in the DEA frontier shift from period $\alpha$ to $\beta$, as measured from DMU $j_{0}$. That is, the frontier has moved forward, generating more output but with less input (see corresponding arrow in Figure 2). As in previous cases, $F S=1$ and $F S<1$ imply no change and loss (shift backward), respectively.

Since $P E / P A$ in Figure 2 is, for example, the DEA score $g_{j_{0}}$ of the period $\alpha$ DMU $j_{0}$ measured by means of the period $\beta$ frontier, we denote it as $g_{j_{0}}\left[D^{\alpha}, F^{\beta}\right]$. Then, from (4), we obtain:

$$
M I_{j_{0}}[\alpha, \beta]=\frac{g_{j_{0}}\left[D^{\beta}, F^{\beta}\right]}{g_{j_{0}}\left[D^{\alpha}, F^{\alpha}\right]} \times\left(\frac{g_{j_{0}}\left[D^{\alpha}, F^{\alpha}\right]}{g_{j_{0}}\left[D^{\alpha}, F^{\beta}\right]} \cdot \frac{g_{j_{0}}\left[D^{\beta}, F^{\alpha}\right]}{g_{j_{0}}\left[D^{\beta}, F^{\beta}\right]}\right)^{1 / 2} .
$$

In (1), letting $x_{i j}^{\alpha}, y_{i j}^{\alpha}=x_{i j}, y_{r j}$, respectively, in period $\alpha, g_{j_{0}}\left[D^{\alpha}, F^{\alpha}\right]$ can be obtained as the optimum of the following FP, which is the classic DEA model:

$$
\begin{array}{cl}
\text { Maximize } & g_{j_{0}}=\frac{\sum_{r=1}^{t} u_{r} y_{r j_{0}}^{\alpha}}{\sum_{i=1}^{m} v_{i} x_{i j_{0}}^{\alpha}} \\
\text { subject to } & \frac{\sum_{r=1}^{t} u_{r} y_{r j_{0}}^{\alpha}}{\sum_{i=1}^{m} v_{i} x_{i j_{0}}^{\alpha}} \leq 1, j=1, \ldots, n, \\
& u_{r}, v_{i} \geq 0, r=1, \cdots, t, i=1, \ldots, m .
\end{array}
$$

$g_{j_{0}}\left[D^{\beta}, F^{\beta}\right]$ can also be obtained using the FP in (7) by replacing $\alpha$ with $\beta$.

While $g_{j_{0}}\left[D^{\alpha}, F^{\beta}\right]$ is obtained as the optimum of

$$
\begin{aligned}
\text { Maximize } & g_{j_{0}}=\frac{\sum_{r=1}^{t} u_{r} y_{r j_{0}}^{\alpha}}{\sum_{i=1}^{m} v_{i} x_{i j_{0}}^{\alpha}} \\
\text { subject to } & \frac{\sum_{r=1}^{t} u_{r} y_{r j_{0}}^{\beta}}{\sum_{i=1}^{m} v_{i} x_{i j_{0}}^{\beta}} \leq 1, j=1, \ldots, n, \\
& u_{r}, v_{i} \geq 0, r=1, \cdots, t, i=1, \ldots, m,
\end{aligned}
$$

this forms the DEA exclusion model (Andersen and Petersen 1993). Finally, we obtain $g_{j_{0}}\left[D^{\beta}, F^{\alpha}\right]$ by using the DEA exclusion model again, but with $\alpha$ and $\beta$ switched.

In the current study, we use panel social indicator data from 97 countries and obtain the catch-up $C U_{j_{0}}[\alpha, \beta]$, frontier shift $F S_{j_{0}}[\alpha, \beta]$, and Malmquist $M I_{j_{0}}[\alpha, \beta]$ indices from period $\alpha$ to $\beta$ for country $j_{0}$. It should be noted that the catch-up index compares the closeness of country $j_{0}$ to the nation stability frontier in each period. The frontier shift index expresses the movement of the nation stability frontier between two periods, while the Malmquist index measures the change in nation stability for country $j_{0}$, taking both the frontier shift and catch-up into consideration. Note that $C U_{j_{0}}$ and $M I_{j_{0}}$ express the movement of country $j_{0}$, whereas $F S_{j_{0}}$ represents the shift of the maximum nation stability, which is composed of those countries having DEA-best nation stability. $F S_{j_{0}}$ thus implies nation stability frontier shift, as measured from the location (viewpoint) of country $j_{0}$, where the frontier shift forward involves moving in the direction of greater positive indicators and smaller negative indicators. We therefore propose each average index for all countries as appropriate indicators of nation stability change on a general level. 
We can also describe DEA ${ }^{-} / \mathrm{MI}$ (negative-DEA/MI) analysis using Figure 2 (hereafter a minus sign superscript "“" designates negative DEA). Suppose that DMU $j_{0}$ has moved from point $\mathrm{A}$ to $\mathrm{B}$, while the DEA rear has shifted from OGH to OIJ between periods $\alpha$ and $\beta$. Then, the $\mathrm{DEA}^{-} /$Malmquist index of DMU $j_{0}$ is:

$$
\begin{aligned}
M I_{j_{0}}^{-}[\alpha, \beta] & \equiv\left(\frac{Q H / Q B}{P G / P A} \cdot \frac{Q J / Q B}{P I / P A}\right)^{1 / 2} \\
& =\frac{Q J / Q B}{P G / P A} \times\left(\frac{P G / P A}{P I / P A} \cdot \frac{Q H / Q B}{Q J / Q B}\right)^{1 / 2} \\
& =C U_{j_{0}}^{-}[\alpha, \beta] \times F S_{j_{0}}^{-}[\alpha, \beta] .
\end{aligned}
$$

Here, $M I_{j_{0}}^{-}[\alpha, \beta]>1$ implies a gain (i.e., increase in the $\mathrm{DEA}^{-}$efficiency score of DMU $j_{0}$ ) from period $\alpha$ to $\beta ; C U_{j_{0}}^{-}[\alpha, \beta]>1$ means that DMU $j_{0}$ has moved farther from the period $\beta$ rear than from that of period $\alpha$; and $F S_{j_{0}}^{-}[\alpha, \beta]>1$ means that the DEA rear has shifted forward, so as to have more outputs with fewer inputs (see corresponding arrow in Figure 2). In DEA $^{-}$nation stability analysis, using the average indices, we can show a nation stability "bad" change in general.

Referring to (6), and denoting, for example, $P I / P A$ as $f_{j_{0}}\left[D^{\alpha}, R^{\beta}\right]$ because it implies the $\mathrm{DEA}^{-}$score of period $\alpha$ DMU $j_{0}$ measured by period $\beta$ DEA rear,

$$
M I_{j_{0}}^{-}[\alpha, \beta]=\frac{f_{j_{0}}\left[D^{\beta}, R^{\beta}\right]}{f_{j_{0}}\left[D^{\alpha}, R^{\alpha}\right]} \times\left(\frac{f_{j_{0}}\left[D^{\alpha}, R^{\alpha}\right]}{f_{j_{0}}\left[D^{\alpha}, R^{\beta}\right]} \cdot \frac{f_{j_{0}}\left[D^{\beta}, R^{\alpha}\right]}{f_{j_{0}}\left[D^{\beta}, R^{\beta}\right]}\right)^{1 / 2},
$$

where each value of $f_{j_{0}}$ can be computed through the FP transformed from (2), as is done with the ordinary DEA/Malmquist index.

\subsection{Cumulative Malmquist index}

Applying data to the FPs of (7) and (8), and through formulas (5) and (6), we can compute the catch-up $C U_{j_{0}}[\alpha, \beta]$, frontier shift $F S_{j_{0}}[\alpha, \beta]$, and Malmquist $M I_{j_{0}}[\alpha, \beta]$ indices. Normally, these indices, for year $\beta$, would be compared to those in the preceding year (i.e., $\alpha=\beta-1$ ). However, such annually successive indices do not seem appropriate when looking across the full 23 -year sample period. We thus employ a "cumulative" index in the spirit of Hashimoto and Haneda (2008). The following parameters are therefore used in the current analysis: $C U_{j_{0}}\left[\alpha_{s}, \beta\right]$, $F S_{j_{0}}\left[\alpha_{s}, \beta\right]$, and $M I_{j_{0}}\left[\alpha_{s}, \beta\right]$, where $\beta=\alpha_{s}, \ldots$. These are then compared to the standard year $\alpha_{s}$ (the beginning of the sample period), so that they measure successive changes from the standard year through to year $\beta$. The cumulative index values when $\beta=\alpha_{s}$ are all 1.

\subsection{Frontier and rear shifter analysis}

As a point of view for analyzing individual countries, we examine each country's influence on nation stability on a general level. Referring to Färe et al. (1994), we employ the following three conditions to determine the countries that caused a frontier forward-shift from the preceding year:

(fa) $\frac{F S_{j_{0}}\left[\alpha_{s}, \beta\right]}{F S_{j_{0}}\left[\alpha_{s}, \beta-1\right]}>1$, (fb) $g\left[D^{\beta}, F^{\beta}\right]=1$, (fc) $g\left[D^{\beta}, F^{\beta-1}\right]>1, \beta=\alpha_{s}+1, \ldots$ 
Likewise, the corresponding three conditions for determining which countries caused a rear backward-shift from the preceding year are:

$$
\text { (ra) } \frac{F S_{j_{0}}^{-}\left[\alpha_{s}, \beta\right]}{F S_{j_{0}}^{-}\left[\alpha_{s}, \beta-1\right]}<1, \text { (rb) } f\left[D^{\beta}, R^{\beta}\right]=1, \text { (rc) } f\left[D^{\beta}, R^{\beta-1}\right]<1, \beta=\alpha_{s}+1, \ldots
$$

\section{Evaluation indicators for nation stability analysis}

To evaluate nation stability, we gathered data for the following six indicators (categorized according to the four aspects depicted in Figure 1).

\section{Internal economy}

Real GDP (per 1,000 persons)

\section{External economy}

Imports/GDP* (\%)

\section{Internal society}

Terrorism* (cases by country where each incident occurred)

Degree of political stability

\section{External society}

Defense expenditure/GDP* $(\%)$

Susceptibility to war

("negative indicator)

These six underlying indicators are based on the following rationale. Real GDP, imports/GDP, terrorism, and defense expenditure/GDP are objective indicators that clearly reflect the level of the four aspects. Real GDP is a chronologically representative economic indicator that expresses national economic activity. Real GDP divided by population substantially indicates nation stability in relation to population scale. So a higher value means the country is more stable in terms of its internal economy. Next, imports/GDP is the self-sufficiency ratio for a country. This ratio indicates external economic circumstances, which reflect the quantities of resources (agricultural products, fossil fuels, mining resources, and self-produced goods) needed for industrial products and services. The more stable the country, the lower this ratio is in relation to national economic scale.

As for terrorism, panic and mistrust damage domestic society tremendously, in addition to actual physical loss. Terrorism is generally defined as actions that influence the attitudes and behaviors of a target group wider than the immediate victims (Mickolus 1980). We consider terrorism to be an indicator of internal society because it generally has a severe negative-impact on the national way of life. In addition, a mission to prevent it typically involves the internal security apparatus. Mirza and Verdier (2008) verified statistically that transnational acts of terrorism such as New York (2001), Madrid (2003), and London (2005) were not representative of most terrorism. In fact, incidents often occur in the country of origin of the perpetrators. Therefore, we adopt total cases of terrorism in each country as a measure of the internal social aspect of its nation stability. The defense expenditure/GDP ratio shows military power in relation to 
GDP. It is desirable for each country to have sufficient power to maintain its external national security. However, excessive force can disturb world peace by intimidating other countries, which may suspect aggression. The higher this indicator, the lower is nation stability.

The remaining two indicators refer to the social system: political stability (internal) and susceptibility to war (external). We add these to account for latent factors that cannot be fully expressed by objective indicators. Degree of political stability and susceptibility to war are indices of the R\&I Country Risk Survey (Rating and Investment Information, Inc.). Each of these indices is assessed using one of five grades $(\mathrm{a}=10, \mathrm{~b}=8, \mathrm{c}=6, \mathrm{~d}=4$, e $=2)$ by experts who are familiar with conditions in the country, and the results are averaged. We therefore have objective indicators and expert opinion indicators playing complementary roles in each of the two social aspects of nation stability.

We collected annual data on these six indicators for 97 countries during 1981-2004. The information was provided by the United Nations Statistics Division ${ }^{1}$ (UNSD), Global Terrorism Database $^{2}$ (GTD) START, Military Balance 1981/1982-2004/2005 (IISS), and the R\&I Country Risk Survey. We generated six data panels, consisting of four negative and two positive indicators. However, we were forced to exclude the year 1993 from the study period because the terrorism data for 1993 was completely missing from the GTD. It should be noted that we complemented the six panels by interpolating a few missing values. In order to perform DEA computations, we employ normalized scores with a mean of 50 and a variance of 100 for each panel. In this way, we treat the extent of deviation within each panel equally across all six indicators.

\section{$5 \quad$ Analysis of nation stability shifts}

\subsection{Country analysis}

Using the cumulative indices, we can obtain nation stability shift graphs for any country of interest. Figure 3 presents such graphs for Switzerland, displaying two forms of three cumulative indices $\left(M I, F S, C U\right.$ and $\left.\mathrm{MI}^{-}, \mathrm{FS}^{-}, \mathrm{CU}^{-}\right)$in DEA and negative DEA evaluation.

Switzerland was on the nation stability frontier $\left(g\left[D^{1981}, F^{1981}\right]=1\right)$ in cross-sectional DEA for the first year (1981). In Figure 3(a), The $M I$ evaluates the nation stability change of a country while accounting for a frontier shift. Note that the nation stability of Switzerland rose, reaching its peak in 2002 (12\% better than in the first year). Also noteworthy is the movement of the nation stability frontier compared to Switzerland's position on the ever-changing annual frontier. The $C U$ measures how much closer to the dynamic frontier of nation stability a country moves each year. However, the cumulative catch-up index of Switzerland is 1 for every year of our study. That is, Switzerland was on the frontier throughout the entire period. The FS expresses the frontier shift measured from the viewpoint of Switzerland. From Eq. (5), we see that the Malmquist and frontier shift indices for Switzerland move together.

Figure 3(b) illustrates the movements of the three cumulative negative indices for Switzerland determined by Eqs. (11) and (12) in the DEA $/ \mathrm{MI}$ analysis (see subsection 3.2). Recall that the $\mathrm{DEA}^{-}$nation stability analysis is a lower-bound evaluation focusing on each country's inferiority (i.e., instability), and thus neglects any superior performance in terms of nation stability. It thus implies the least favorable evaluation of each country's nation stability versus a more favorable evaluation, as provided by the DEA nation stability analysis. The $C U^{-}$, $\mathrm{FS}^{-}$, and $\mathrm{MI}^{-}$indices indicate the change of distance from the rear, the rear shift, and the nation stability shift of a country, respectively. In figure 3(b), the $\mathrm{MI}^{-}$shift shows that Switzerland's nation stability of lower-bound evaluation rose during the entire study period, as did its upper-bound evaluation. Unlike the upper-bound evaluation, its $\mathrm{FS}^{-}$and $\mathrm{CU}^{-}$moved largely because they are measured by the rear, which is composed of the most unstable from the viewpoints of Switzerland. In particular, its $M I^{-}$did not move much in 1991, although its $C U^{-}$ was dramatically far from the rear. That is, its $\mathrm{CU}^{-}$change was due to the rear shift because its 
$F S^{-}$reached its nadir in 1991. Thus, the sets of three cumulative indices give us much valuable information about the nation stability shifts for each country.

Figure 4 shows the nation stability shifts of the USA, China, and Iraq, respectively, in both DEA evaluations. Note that the cross-sectional evaluations for the first year (1981) of our study, which treat each country as a separate DMU, show USA initially on the frontier and Iraq on the rear $\left(f\left[D^{1981}, R^{1981}\right]=1\right)$.

From the cumulative $M I^{-}$in Figure 4a, we see that the USA's nation stability improved during 1991-2000, but fell in 1991 and 2001. The MI of the USA declined during 1990-1992, and thereafter increased until 2003. Note that, for the USA, the Gulf War occurred in 1991 and the September Eleven Attacks in 2001. In the case of the USA, the $\mathrm{MI}^{-}$was more sensitive to historical events than the $M I$. For China (Figure 4b), the $M I$ reached its peak in 1985, thereafter decreasing dramatically to its nadir in 1990. This shows that China's nation stability rose until 1985, and then declined from 1985 to 1990 (in which it was 34.5\% worse than in the first year). Unlike that of the USA, the $M I^{-}$of China showed hardly any changes during 1985-1990. Note that the June Fourth Incident in Tiananmen Square occurred in 1989. As Figure $4 \mathrm{c}$ shows, in contrast with the above two countries, Iraq's $M I$ and $M I^{-}$show similar trends. Viewing the $M I^{-}$index, we see that the stability of Iraq was weakest in 1984, and 27\% worse than in 1981. Its stability then rose to 1.035 in 1990, which is the only year in which Iraq was able to escape from the rear. The $\mathrm{MI}^{-}$of Iraq fell dramatically after 2002, and it ended the study period at a 2004 level $22 \%$ below that of 1981 . That is, it was more unstable then than it had been in 1981. The $M I$ shows changes similar to those in the $M I^{-}$, and decreases together with the $M I^{-}$. Note that in our study period Iraq experienced three wars: the First Gulf War (1980-1988), the Second Gulf War (1990-1991), and the Iraq War (2003).

In the cases of the USA and China, we can understand the changes in nation stability that reflected the epoch by paying attention to $M I$ or $M I^{-}$. For Iraq, both indices indicated similar changes in nation stability. In other words, our results are dependent on whether influences, such as the cases, appeared in the bad or good points of the country in nation stability. Furthermore, this also depends on the number of instances of superiority and inferiority of a country, compared to the other countries. In this way, we can demonstrate the shifts in nation stability for each country, by focusing on two different nation stabilities simultaneously.

\subsection{Nation stability shifts in general}

To evaluate how nation stability changed in general during our study period 1981-2004, we computed the average for each cumulative index across all countries $M I[1981, \beta]$, $F S[1981, \beta]$, and $C U[1981, \beta], \beta=1981, \ldots, 2004(\beta \neq 1993)$. The $M I$ indices on average describe the movements made by the nation stability of the average country. The $F S$ indices on average indicate shifts of the general frontier nation stability, from the viewpoint of the average country. The $C U$ indices on average indicate the annual gaps in nation stability between the frontier and an average country, which are gaps of nation stability on a general level. Note that we employ geometric rather than arithmetic means when averaging the $M I, F S$, and $C U$ indices, because they are all multiplicative in nature.

Figure 5a shows the shift of the cumulative $M I, F S$, and $C U$ indices on average in the DEA evaluation. In the early years of the study period, $M I$ indices did not change much. After 1989, they decreased, and then improved gradually from 1994 onward. However, relative to 1981, MI was still down nearly $10 \%$ when the study period ended in 2004 . The FS graph shows a general upward trend throughout the study period, reaching a peak in 2003 (approximately $9 \%$ improvement over 1981). That is, the frontier of nation stability on a general level improved gently but fairly consistently from 1981 to 2004 . However, the $C U$ worsened from 1988 to 1992 , and remained low at the end of the study period (2004, down $15.4 \%$ relative to 1981). This trend means that the average country diverged about $0.8 \%$ more every year from the 
annual nation stability frontier. Combining the graphs of $M I$ and $F S$, we can see that after 1988 the average $M I$ generally fell, and the average $F S$ generally rose.

Figure $5 \mathrm{~b}$ shows the average shift of the cumulative $\mathrm{MI}^{-}, \mathrm{FS}^{-}$, and $\mathrm{CU}^{-}$indices in the negative DEA evaluation. In the early years of the study period, $\mathrm{MI}^{-}$indices did not show a consistent pattern of change, but did show steady decreases after 1989. Although $\mathrm{MI}^{-}$rose roughly in parallel with $M I$ during the second half of the study period (1994 onward), it differed by surpassing 1, reaching its peak in 2003 (4.1\% better than in its first year). From the viewpoint of lower-bound evaluation, this index of nation stability did not change much on average. However $\mathrm{MI}^{-}$did worsen by $6.5 \%$ between 1989 and 1992 . Focusing on the rear shift, $F S^{-}$showed repeated ups and downs, with a maximum year-on-year change of $-16.4 \%$ (1990 to 1991). There was no consistent trend in the rear shifts. Our results show that the nation stability of unstable countries involves large swings change because the rear shift depends on the stability of the most unstable countries. We surmise that the nation stability of unstable countries moves in this fashion because discontented elements are actualized more easily there than in stable countries.

Through these twin analyses of nation stability on a general level, we observed that the year 1989, when the cold war ended, was a watershed. From 1989 to 1992, nation stability at large worsened significantly (by $14.8 \%$ for $M I$, and $6.5 \%$ for $M I^{-}$, compared to 1981). It appears that the nadir occurred in 1992, because many countries suffered a large negative-impact on their nation stability when the world structure changed, especially in 1991, when the Soviet Union collapsed (see Figure 9). Furthermore, the annual gaps in nation stability between the most stable country and the average country became clear after 1989. We think that these gaps are another result of structural change after the cold war ended.

\subsection{Frontier and rear shifter countries}

The general frontier and rear of nation stability moved during the study period, as shown in Figure 5 and is discussed in the preceding subsection. Now, let us examine which countries shifted the frontier forward and which shifted the rear backward, year by year, according to Eqs. (13) and (14).

The countries that appear most frequently on the list of frontier-forward and rear-backward shifters are as follows.

\section{Frontier-forward shifter}

16 [Switzerland], 10[USA], 9[Singapore]

\section{Rear-backward shifter}

10[Iraq], 7[Peru], 6[North Korea]

Switzerland, USA, and Singapore, as the main frontier shifters, were the greatest contributors to improved nation stability among the best performing countries. Iraq, Peru, and North Korea, as the main rear shifters, were most responsible for the declining nation stability among the worst performing countries. In particular, Switzerland showed the best stability of cross-sectional DEA during the study period, and always achieved the position of the most stable country in our analysis. These findings help clarify the shifts of nation stability at a general level during the study period (see Figure 5).

Singapore exhibited other interesting results in this metric, even though Singapore was a frontier shifter. Singapore also appeared twice in our analysis as a rear back shifter. Note here that the nation stability of Singapore was singular in our study, because it occasionally realized both the DEA best and the DEA ${ }^{-}$worst nation stability. Furthermore, Singapore appeared as a regular country of high rank only in DEA (stable country), and it was low rank in $\mathrm{DEA}^{-}$(unsta- 
ble country) throughout our study period. As for the high stability level of Singapore, the domestic (internal) social aspect was highly rated, and systematically maintained by its legal system. However, Singapore was judged unstable in its economic aspects, because it depends heavily on trade and does not have enough natural resources.

In contrast, Iraq and North Korea are dubious members of the international community, particularly regarding alleged weapons of mass destruction. In particular, Iraq was embroiled in war for many years of the study period. Peru often shifted the rear during the 1980s because of political instability (many terror incidents occurred). In relation to nation stability in general, wobbly rear shifts were contingent on these three countries. Therefore, they are the most unstable in our analysis.

\section{Analysis of unified and split countries}

Unified Germany, along with the split Soviet Union, Czechoslovakia, Yugoslavia and their successor countries, are included as DMUs in our analysis. However, the traditional method of DEA/MI does not enable us to grasp these countries' changes in nation stability before and after the year of unification or split. We propose a new approach to both cases (DMU merger and split) by utilizing the following two steps: the handling of data, and the application of DEA/MI to cases of merger or split.

\subsection{Method for analyzing merger and split}

\section{Handling of data}

When analyzing the merged/split DMUs, we naturally encounter some blanks in the data panels because we no longer observe data related to the old national boundaries, such as separate data for East and West Germany after reunification in 1990. The normal computation of DEA/MI is impractical due to the incomplete panel data. To investigate changes in nation stability before and after a unification or split, it is much better to consider the situation as a series of DMUs, than to analyze the new and old DMUs separately. To this end, we devised a new way of handling the data. As shown with arrows and coloring in Figure 6, we apply a successor DMU's data to the data of its predecessors, as if they had continued to exist in the post-merger period. In the same way, data for a divided DMU are applied to the data of its successor DMUs, as if they had already existed during the pre-split period. Note that the DMUs of each year in the portion that we colored actually indicate the same DMU. In other words, the succession of DMUs is tracked even though they have been formally designated as different DMUs. Therefore, we can compute DEA/MI for unified or split countries, and treat them as a series of countries that existed continuously during the entire study period. Note that care must be taken in regard to variability in the number of DMUs, because the total number of DMUs is significant when averaging the $M I, C U$, and FS indices annually.

\section{DEA/MI application to cases of merger or split}

We can describe the graphs of DMUs with merger or division by using the handling data mentioned above. Figure 7a shows the MI shifts of hypothetical DMU P1 and DMU P2, which merged in year s, and are thereafter regarded as being a single DMU S. However, there is a serious problem, in the sense that we cannot capture all three DMUs' chronological changes relatively through the use of only two graphs, due to discordance in and after year s, despite continuing as the new DMU S (i.e., maintaining the same DMU identity). In the case of a split, the traditional method of DEA/MI is similarly inadequate. Because unification and split are historically significant events, we need to find a way to express clearly the shifts before and after the 
year of unification or split.

We propose the following new application of DEA/MI to both cases (merger and split), with the aim of evaluating the impact of countries' unification or split. We designate the merger/split year as the standard year $\alpha_{s}=$ year of merging/dividing in computing the cumulative indices $\left(M I_{j_{0}}\left[\alpha_{s}, \beta\right], C U_{j_{0}}\left[\alpha_{s}, \beta\right]\right.$, and $\left.F S_{j_{0}}\left[\alpha_{s}, \beta\right]\right)$. Note that these indices are here computed even when $\beta<\alpha_{s}$ following the definitions described in subsection 3.2. We can then grasp their shifts before and after the standard year, because the cumulative index values when $\beta=\alpha_{s}$ will all be 1 . As a result, we can simultaneously draw the graphs of all three DMUs, as shown in Figure $7 \mathrm{~b}$.

In this way, we can comprehend the chronological stability of a unified or split country appropriately. (See also Haneda et al. (2009) for a DEA/MI application to the merger of municipal administrations.)

\subsection{Analysis of a unified country}

Figure 8 shows the shifts in $M I$ and $\mathrm{MI}^{-}$for successor (reunified) Germany relative to the standard year 1990. These graphs cover both pre- and post-unification, and indicate chronological changes in $M I$ and $M I^{-}$relative to the standard year. In the pre-unification period, there was no consistent trend in nation stability because the annual variations of $M I$ and $\mathrm{MI}^{-}$were large. The indices of both East and West Germany regressed together as 1990 (the reunification year) approached, then the reunified (successor) Germany's nation stability gradually improved. In the post-unification period, $M I$ and $\mathrm{MI}^{-}$improved on average $6.2 \%$ and $5.9 \%$, respectively, relative to the merger year 1990 . Both of these indices for the predecessor countries were on average approximately $2 \%$ and $4 \%$ below the level of post- 1990 . Therefore we can see that the reunification of Germany improved nation stability in the post-unification period.

Comparing the $M I$ and $M I^{-}$for East and West Germany before 1990, we see that the stability $(M I)$ related to the upper-bound evaluation for East Germany was better than that for West Germany, but the instability $\left(M I^{-}\right)$related to the lower-bound evaluation for East Germany was worse than that for West Germany. West Germany was one of the more stable countries in our ranking of both cross-sectional evaluations for the pre-unification period, but it did not have any preeminent factors (good or bad) in regard to nation stability. In contrast, East Germany had outstanding faults, if we view it during one phase, but it was a stable country during a different phase. In sum, we find that the reunified Germany steadily improved its nation stability by both enhancing the virtues and making up for the shortcomings that had prevailed during the era of divided East and West Germany.

\subsection{Analysis of split countries}

In Figure 9, we illustrate the break-up of the Soviet Union, which was the representative case of a split country in our study. We adopted the splitting year 1991 as the standard year for computing the cumulative indices. We present all graphs for the Soviet Union and every successor country. The single graph before 1991 shows shifts in the nation stability $(M I)$ of the Soviet Union, and the 15 graphs after 1991 indicate changes in the nation stability $(M I)$ of the 15 successor countries. Viewing the pre-1991 graph, we see that the nation stability of the Soviet Union declined sharply after 1988, and was 58\% lower in 1991 than it had been at its peak in 1987 (it remained at a comparatively high level from 1981 to 1988). After 1991, most of the successor countries, including Russia, struggled for about a decade to improve their nation stability. However, the Baltic countries (Estonia, Latvia, and Lithuania) improved their stability relatively quickly in the post-split period, eventually reaching peaks that were approximately 39-46\% better than in the splitting year. These three countries successfully shed the disorder that fol- 
lowed the Soviet Union's break-up, re-established their own identity, and improved their nation stability. We thus see that the Soviet Union's break-up had a strong negative-impact on the nation stability of most of its successor countries.

Let us now look at three cases of split countries together. Figure 10 portrays the shifts of $\mathrm{MI}$ and $\mathrm{MI}^{-}$for the Soviet Union, Yugoslavia, and Czechoslovakia. Note that the standard year is defined as the respective splitting year $\alpha_{\mathrm{s}}=t$, which was fixed as the benchmark. Looking at the shifts of MI (Figure 10a), we see that Czechoslovakia's nation stability began to worsen dramatically about three years before the split (similar to the case of the Soviet Union), and ended up $49 \%$ lower than it had been six years before the splitting year. Like its MI, Czechoslovakia's $\mathrm{MI}^{-}$started to decline three years before the split, sinking over $10 \%$ compared to year $\mathrm{t}-6$ (Figure 10b). In the case of Yugoslavia, the $M I$ did not fall as much as in the Soviet Union or Czechoslovakia, but its $\mathrm{MI}^{-}$deteriorated sharply. Yugoslavia's upper-bound evaluation began to fall five years before the split, but its instability (lower-bound evaluation) dropped suddenly, falling more than $55 \%$ in the two years before the split. In contrast, for the Soviet Union and Czechoslovakia, both indices began to drop at roughly the same time. We surmise that the deterioration of $M I$ precipitated the decline of $M I^{-}$in Yugoslavia. However, in general, each of three countries had one index drop approximately $50 \%$ (or more) compared to a point several years before the split. So, it is reasonable to conclude that the countries' splits resulted from the precipitous declines in their Malmquist Indices. Thus, we could verify catastrophic decays in nation stability for the split countries in this study. This result may be valid for most countries that have split.

\section{$7 \quad$ Summary and conclusions}

This paper presented a new DEA methodology for analyzing shifts in nation stability, and applied it to data for the period 1981-2004. Nation stability was defined as the state of a country's social and economic system. In contrast to earlier researchers, we incorporated influences emerging from each country, by measuring its external effect on the nation stability of other countries. Applying panel data from 97 countries to both DEA/MI and DEA $/ \mathrm{MI}^{-}$analyses, we were able to evaluate shifts in nation stability, which in the past have been difficult to quantify.

Shifts in each country's nation stability were analyzed using the cumulative catch-up, frontier shift, and Malmquist indices, via both DEA and DEA ${ }^{-}$. We differentiated stable countries and unstable countries within the set of 97 countries. Our analyses of nation stability at the country level found that Switzerland was the most stable in terms of the stability frontier throughout the entire study period, while Iraq was the most unstable in terms of the stability rear for every year except 1995 . On a general level, the gaps in nation stability expanded after the cold war ended, which means that the most stable countries were increasing their stability, while the other countries were experiencing reduced stability. In other words, the end of the cold war marked a turning point in regard to nation stability.

We also analyzed countries that merged or split during the study period. We visually demonstrated shifts for unified or split countries, by graphing the reunified Germany and the successor countries of the Soviet Union, Czechoslovakia, and Yugoslavia. It is noteworthy that the nation stability of each split country worsened by approximately $50 \%$, or more, compared to a point several years before their respective splits. Therefore, we surmise that countries' splits arise as a result of significant drops in nation stability. Thus, we were able to verify catastrophic decays in nation stability for all the split countries in this study.

This study enabled us to quantify shifts in a country's nation stability, a concept that has importance for policy makers, and for international relations. In unstable countries, improving nation stability is a specific remedy for uplifting civil QOL. Many international organizations could utilize this concept for their specialized activities (e.g., agreements about border police, which can use indicators of (in)stability to deal with threats from foreign countries, and other 
decision-making related to homeland security).

From a methodological point of view, we introduced a new DEA/MI application for country mergers and splits, which enabled us to present the DEA/MI shift graphs that show both new and old (merged or split) DMUs together. This approach provides a good way to comprehend chronological shifts in DEA/MI before and after a country merger or split. We hope that such innovations will open up new directions in the development and application of DEA/Malmquist index-based models.

\section{Notes}

1 GTD web page: http://www.start.umd.edu/gtd/.

2 UNSD web page: http://data.un.org/Browse.aspx?d.

\section{References}

Andersen, P. \& Petersen, N. C. (1993). A procedure for ranking efficient units in data envelopment analysis. Management Science, 39(10), 1261-1264.

Banker, R. D., Charnes, A. \& Cooper, W. W. (1984). Some models for estimating technical and scale inefficiencies in data envelopment analysis. Management Science, 30(9), 1078-1092.

Blomberg, S. B. \& Hess, G. D. (2006). How much does violence tax trade? Review of Economics \& Statistics, 88(4), 599-612.

Bond, D., Bond, J., Oh, C., Jenkins, J. C. \& Taylor, C. L. (2003). Integrate data for events analysis (IDEA). Journal of Peace Research, 40(6), 733-745.

Charnes, A., Cooper, W. W. \& Rhodes, E. (1978). Measuring the efficiency of decision making units. European Journal of Operational Research, 2, 429-444.

Cooper, W. W. Seiford, L. M. \& Tone, K. (2000). Data Envelopment Analysis: A Comprehensive Text with Models, Applications, References and DEA-Solver Software. (Boston: Kluwer Academic Publisher)

Doyle, J. R., Green, R. H. \& Cook, W. D. (1995). Upper and lower bound evaluation of multiattribute objects: Comparison models using linear programming. Organizational Behavior and Human Decision Processes, 64(3), 261-273.

Färe, R., Grosskopf, S., Norris, M. \& Zhang, Z. (1994). Productivity growth, technical progress, and efficiency change in industrialized countries. American Economic Review, 84(1), 66-83.

Goldstein, J. S., (1992). A conflict-cooperation scale for WEIS events data. Journal of Conflict Resolution, 36(2), 369-385.

Haneda, S., Hashimoto, A. \& Tsuneyoshi, T. (2009). Evaluating administrative efficiency change in the post-merger period: A study on Ibaraki prefecture (1979-2004). Department of Social Systems and Management Discussion Paper Series 1233, University of Tsukuba. Retrieved from http://www.sk.tsukuba.ac.jp/SSM/libraries

Hashimoto, A. (1993). Evaluating baseball batters using DEA. Communications of the Operations Research Society of Japan, 38(3), 146-153 (In Japanese).

Hashimoto, A. \& Ishikawa, H. (1993). Using DEA to evaluate the state of society as measured by multiple social indicators. Socio-Economic Planning Sciences, 27(4), 257-268. 
Hashimoto, A. (1996). A DEA selection system for selective examinations. Journal of the Operations Research Society of Japan, 39(4), 475-485.

Hashimoto, A. (1997). A ranked voting system using a DEA/AR exclusion model: A note. European Journal of Operational Research, 97(3), 600-604.

Hashimoto, A. \& Kodama, M. (1997). Has livability of Japan gotten better for 1956-1990?: A DEA approach. Social Indicators Research, 40, 359-373.

Hashimoto, A. \& Haneda, S. (2008). Measuring the change in R \&D efficiency of the Japanese pharmaceutical industry. Research Policy, 37(10), 1829-1836.

Hashimoto, A., Sugita, T. \& Haneda, S. (2009). Evaluating shifts in Japan's quality-of-life. Socio-Economic Planning Sciences, 43(4), 263-273.

Malmquist, S. (1953). Index numbers and indifference surfaces. Trabajos de Estatistica, 4, 209-242.

Mirza, D. \& Verdier, T. (2008). International trade, security and transnational terrorism: Theory and a survey of empirics. Journal of Comparative Economics, 36, 179-194.

Mickolus, E. F. (1980). Transnational Terrorism: A Chronology of Events 1968-1979. (Westport, CT: Greenwood Press)

Murias, P., Martinez, F. \& de Miguel, C. (2006). An economic wellbeing index for the Spanish provinces: A data envelopment analysis approach. Social Indicators Research, 77, 395-417.

Murias, P., de Miguel, J. C. \& Rodríguez, D. (2008). A composite indicator for university quality assessment: The case of Spanish higher education system. Social Indicators Research, 89, 129-146.

Nitsch, V. \& Schumacher, D. (2004). Terrorism and international trade: An empirical investigation. European Journal of Political Economy, 20, 423-433.

Reisman, A., Oral, M. \& Gattoufi, S. (2002). Absolutely positively operations research: 50 years of contributions by William Wagner Cooper. GSM Working Paper 5, Sabanci University.

Rotberg, R. I. (2003). Failed states, collapsed states, weak states: Causes and indicators. (In R. I. Rotberg (Ed.), State Failure and State Weakness in a Time of Terror (pp. 1-25). Washington DC: Brookings Institution Press)

Rotberg, R. I. (2004). The failure and collapse of nation-states: Breakdown, prevention, and repair. (In R. I. Rotberg (Ed.), When States Fail: Causes and Consequences (pp. 1-49). Princeton University Press)

Somarriba, N. \& Pena, B. (2009). Synthetic indicators of quality of life in Europe. Social Indicators Research. Social Indicators Research, 94, 115-133.

Thanassoulis, E. (2001). Introduction to the Theory and Application of Data Envelopment Analysis: A Foundation Text with Integrated Software. (Boston: Kluwer Academic Publisher)

Yamada, Y., Matsui, T. \& Sugiyama, M. (1994). An inefficiency measurement method for management systems. Journal of the Operations Research Society of Japan, 37(2), 158-168 (In Japanese).

Zhu, J. (2001). Multidimensional quality-of-life measure with an application to Fortune's best cities. Socio-Economic Planning Sciences, 35, 263-284. 


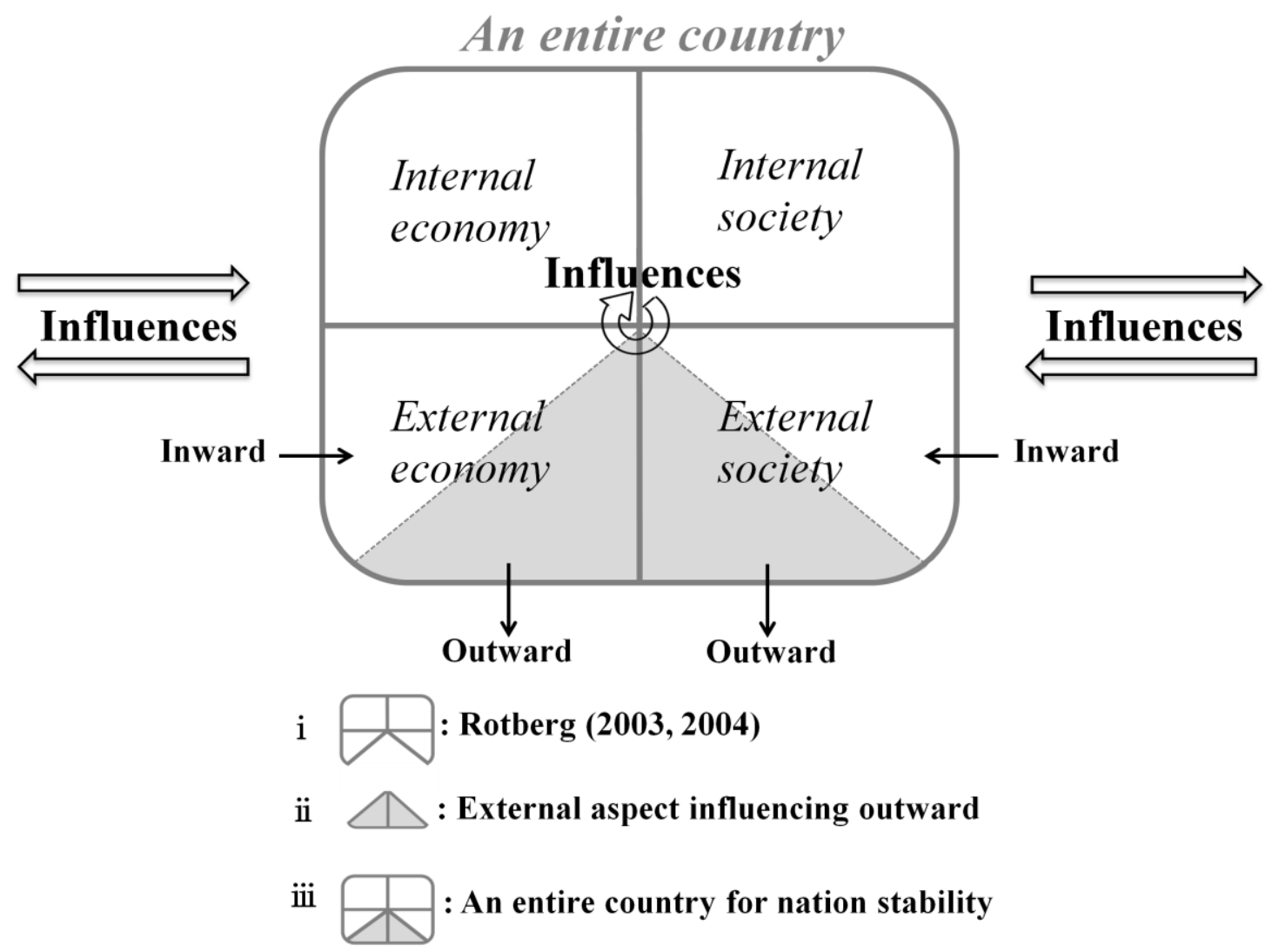

Fig. 1. The four aspects of a country that constitute its nation stability 


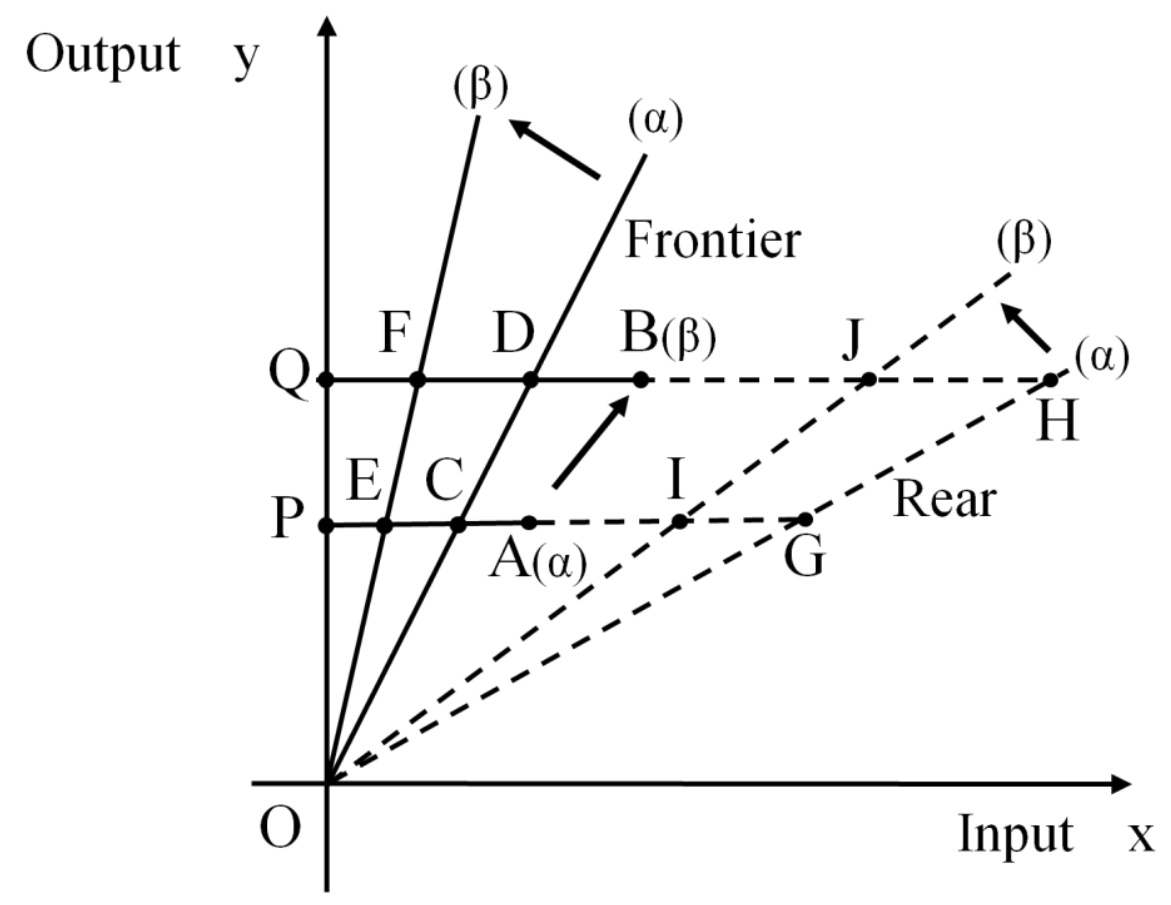

Fig. 2. DEA efficiency changes with the frontier and rear shifting over time 


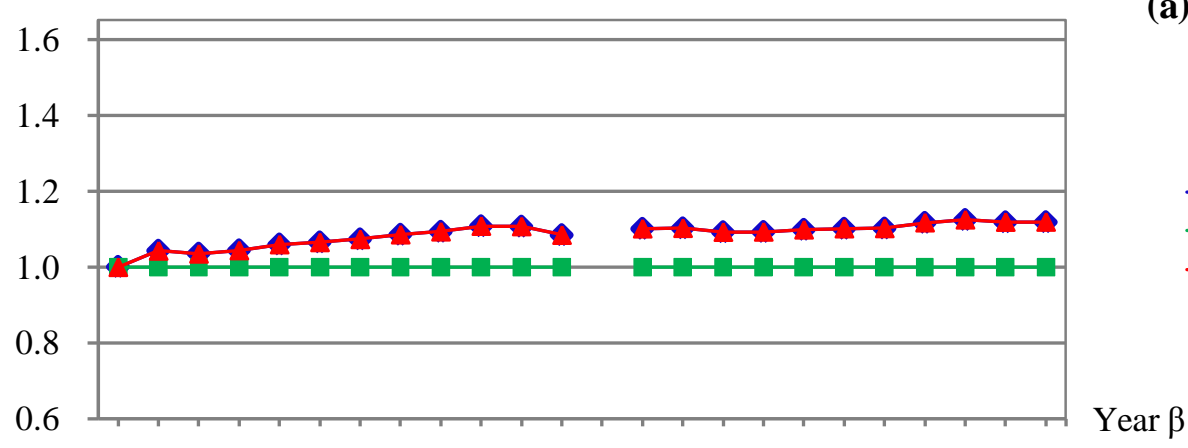

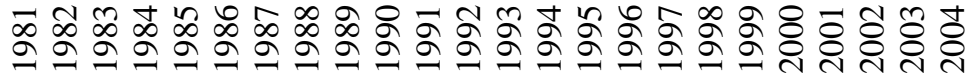

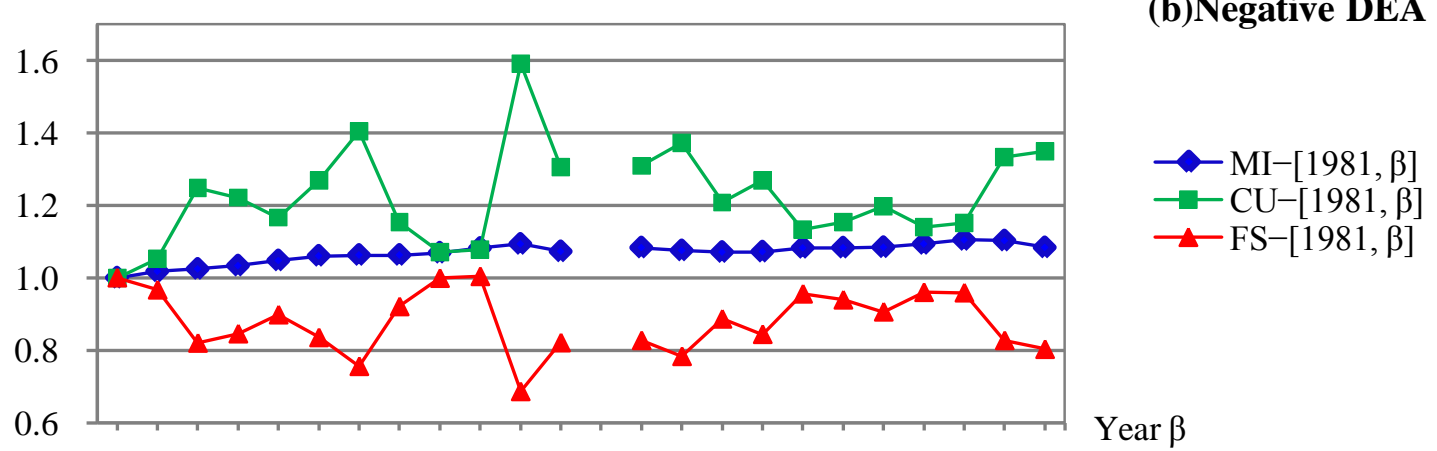

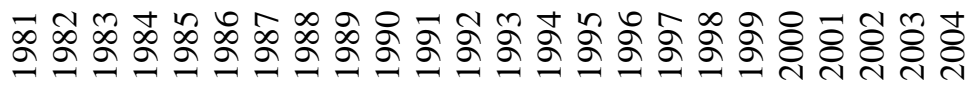

(a) DEA

$\multimap \mathrm{MI}[1981, \beta]$

$-\mathrm{CU}[1981, \beta]$

$\simeq \mathrm{FS}[1981, \beta]$

Fig. 3. Cumulative catch-up, frontier shift, and Malmquist indices for Switzerland 


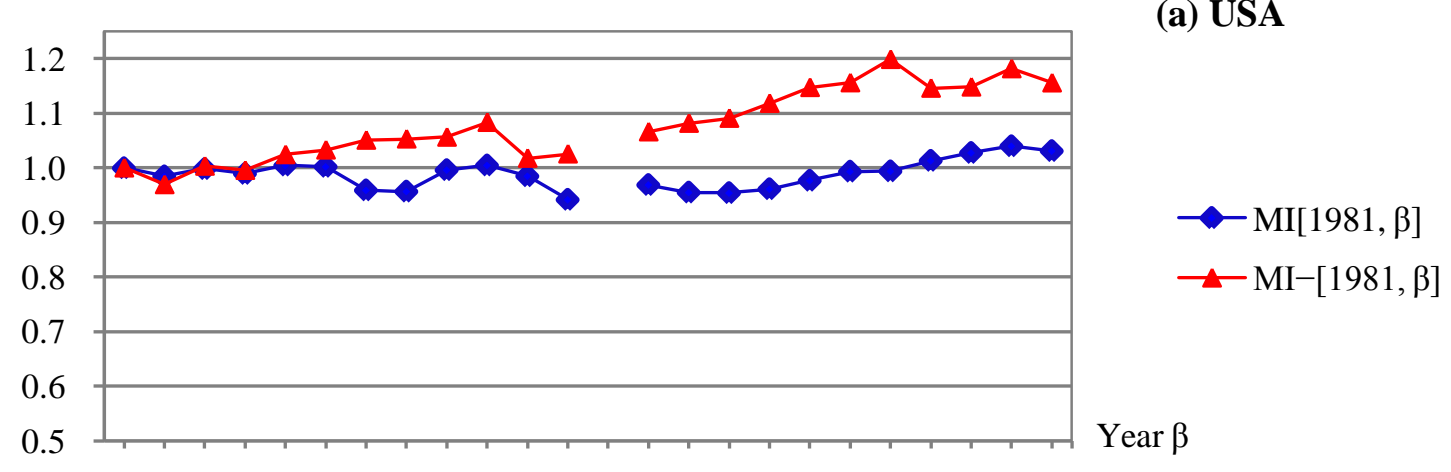

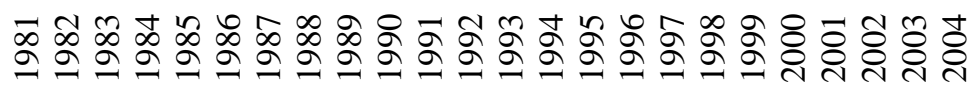

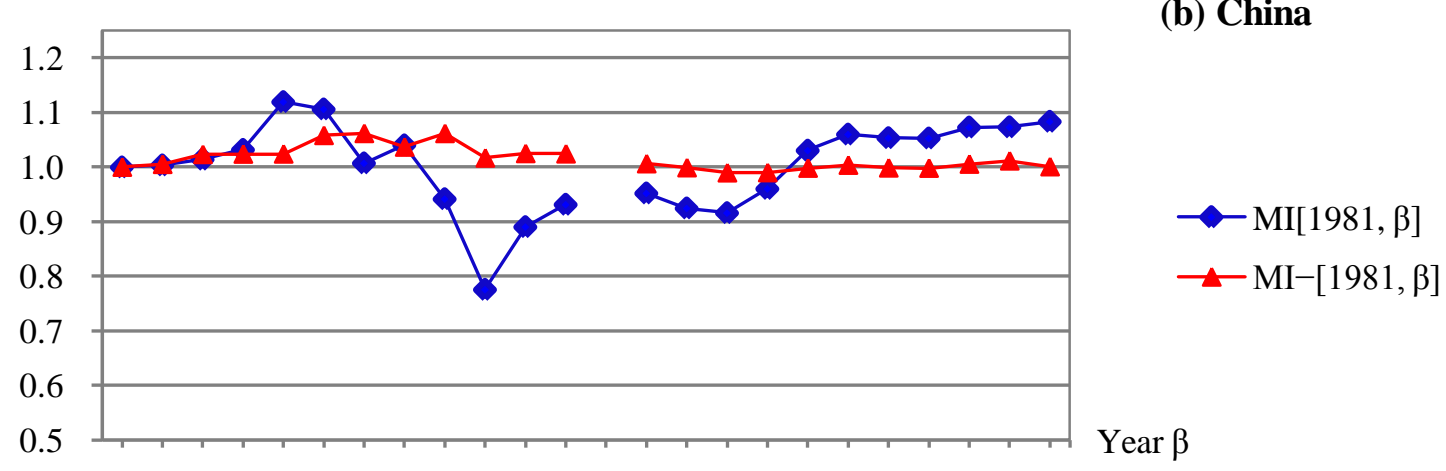

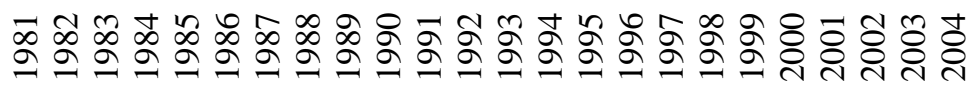

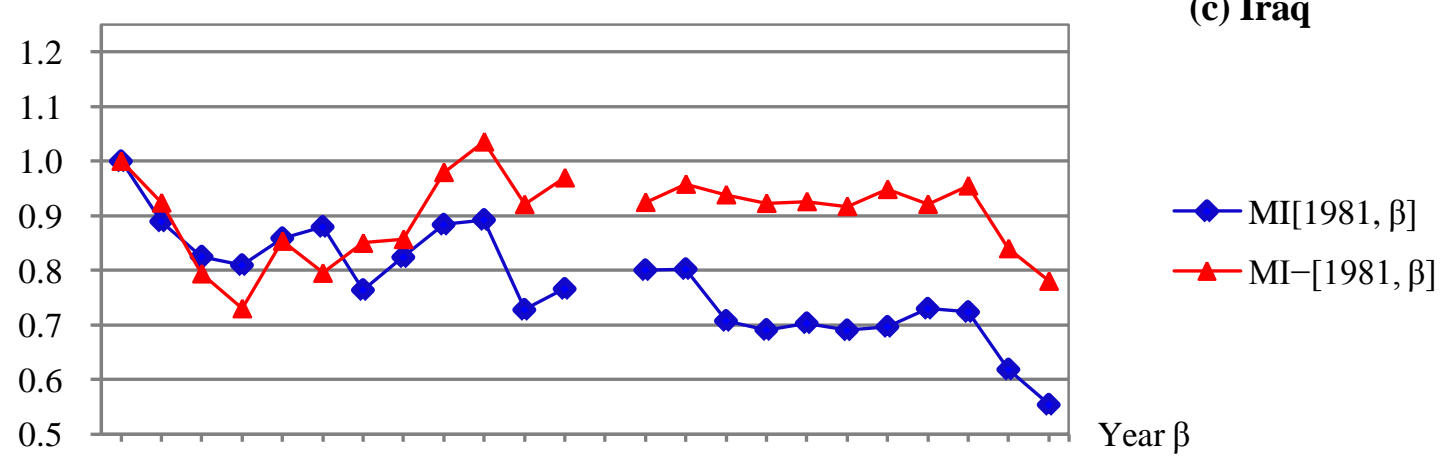

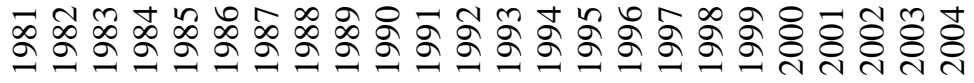

Fig. 4. Cumulative $M I$ and $M I^{-}$indices for three selected countries 


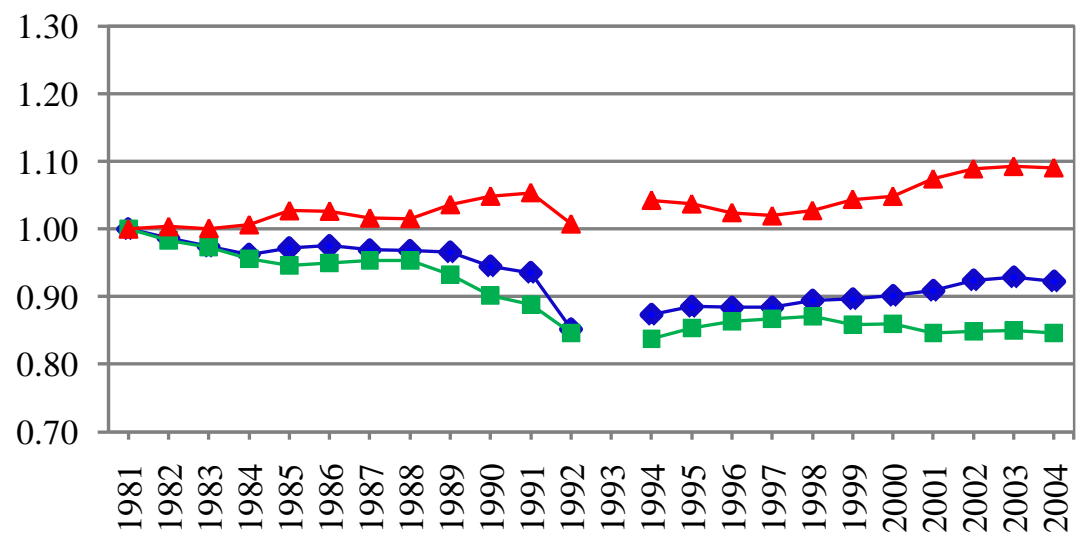

(a) DEA

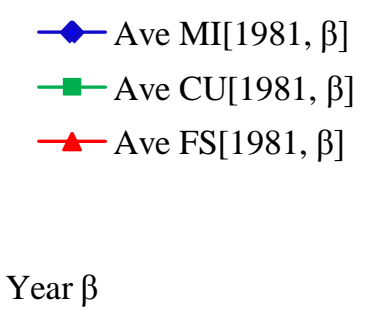

。

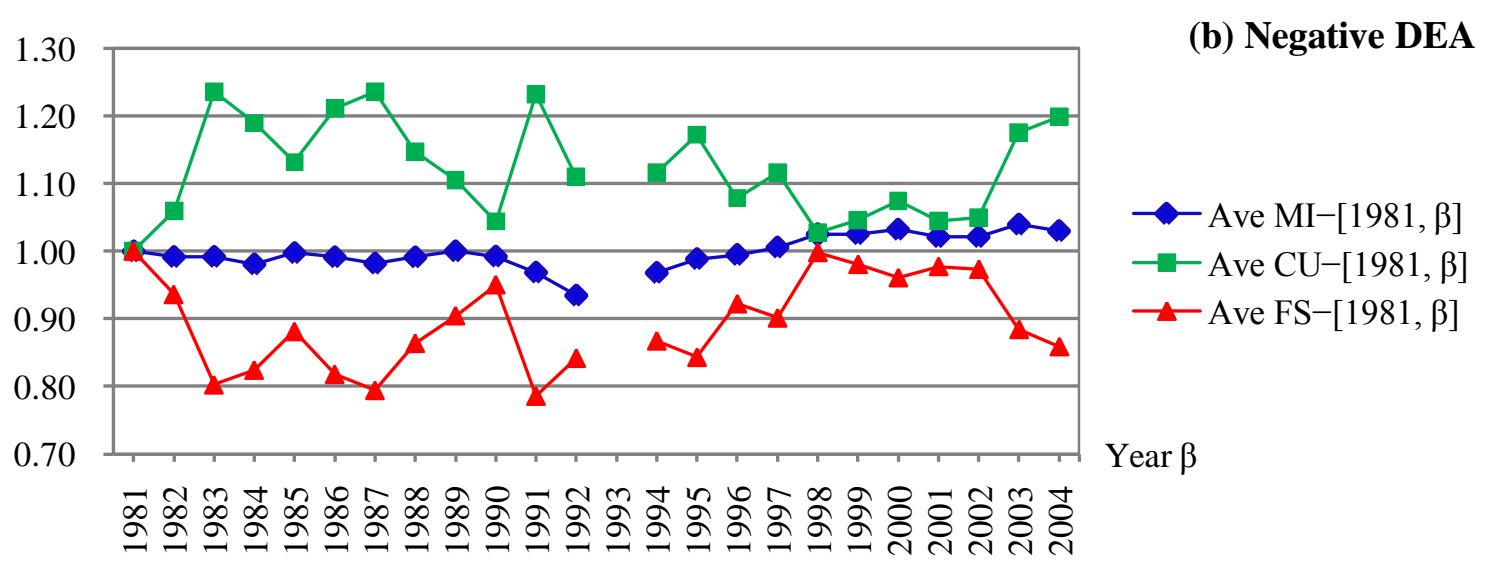

Fig. 5. Nation stability shifts in general 1981-2004 


\begin{tabular}{|c|c|c|c|c|c|c|c|c|}
\hline & & \multicolumn{7}{|c|}{ year } \\
\hline & & $\mathrm{s}-3$ & $\mathrm{~s}-2$ & $\mathrm{~s}^{-1}$ & 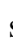 & $s+1$ & $s+2$ & $s+3$ \\
\hline \multirow{2}{*}{ predecessor } & DMU P1 & O & ○ & $\circ$ & & 0 & ० & o \\
\hline & DMU P2 & ० & ○ & ० & & ० & ० & ० \\
\hline successor & DMU S & & & & & o & o & o \\
\hline
\end{tabular}

year s: merged year $\rightarrow$ : copying data

\begin{tabular}{|c|c|c|c|c|c|c|c|c|}
\hline & & \multicolumn{7}{|c|}{ year } \\
\hline & & $t-3$ & $\mathrm{t}-2$ & $\mathrm{t}-1$ & $\mathrm{t}$ & $\mathrm{t}+1$ & $t+2$ & $t+3$ \\
\hline predecessor & DMU P & o & ○ & ○ & ○ & & & \\
\hline \multirow[t]{3}{*}{ successor } & DMU S1 & o & ○ & o & ○ & ० & ० & ○ \\
\hline & DMU S2 & ० & o & o & ० & O & O & O \\
\hline & DMU S3 & 0 & 0 & o & ○ & o & o & o \\
\hline
\end{tabular}

Fig. 6. Creating continuity of data set for merged DMUs and split DMUs 


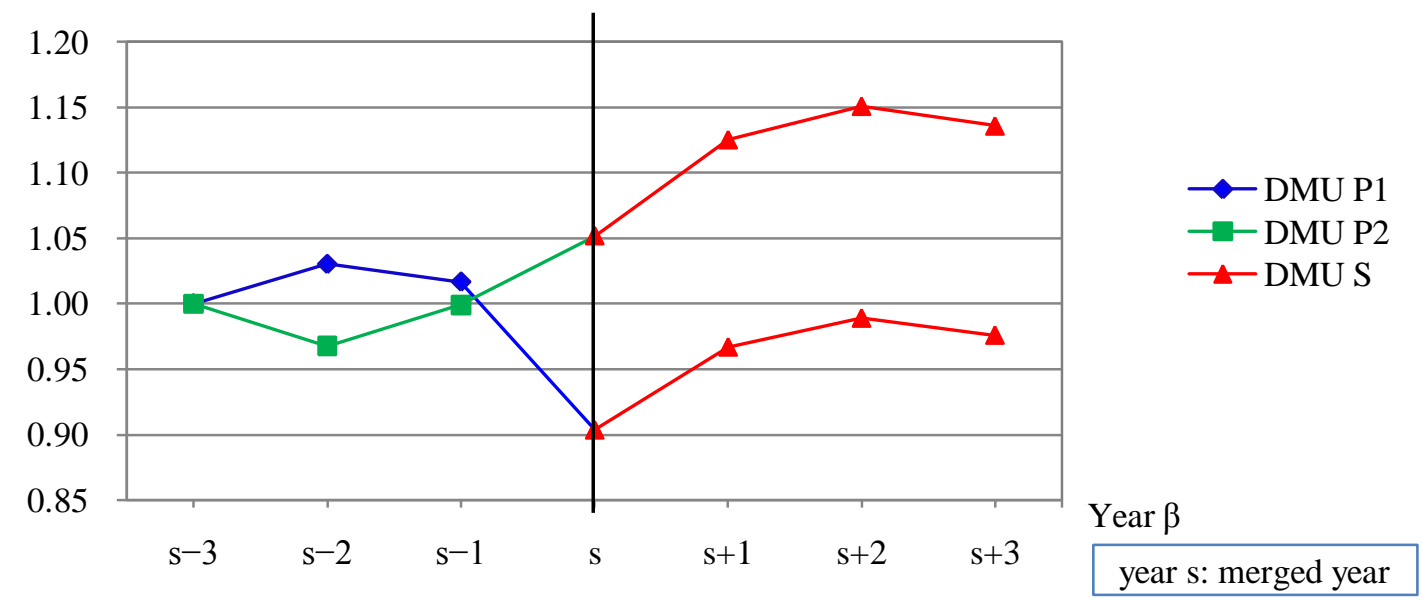

(a) $M I[s-3, \beta](\beta=s-3, \ldots, s+3)$

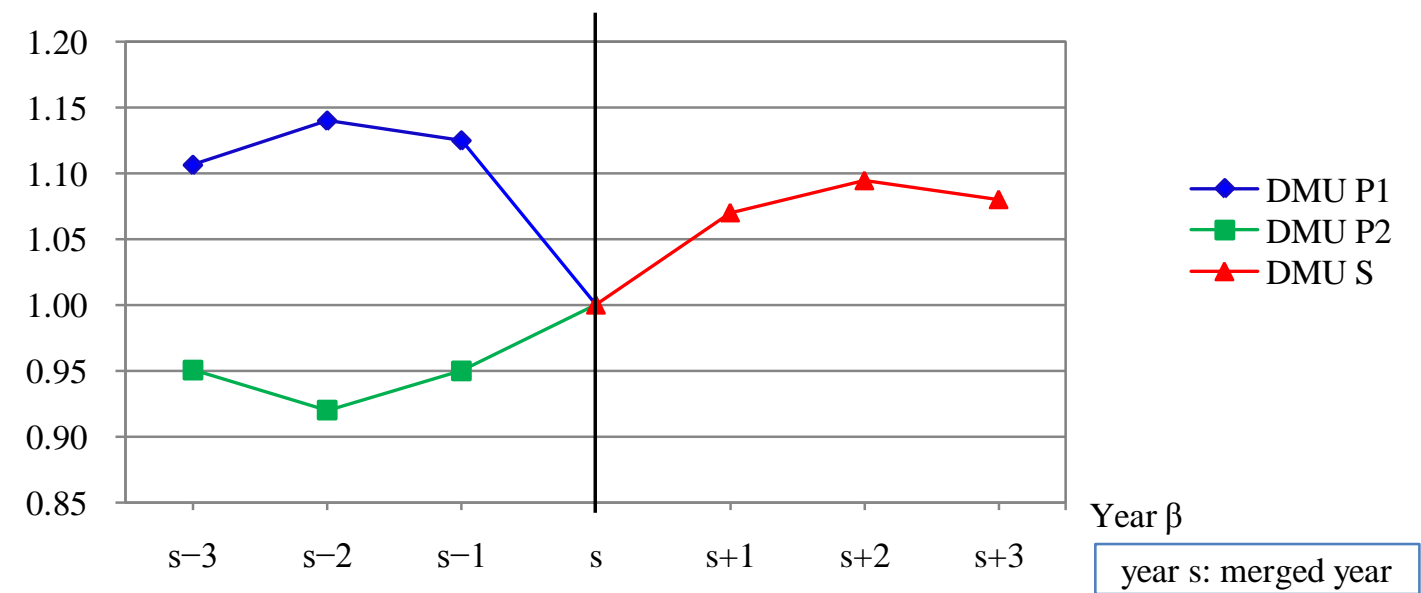

(b) $M I[s, \beta](\beta=s-3, \ldots, s+3)$

Fig. 7. Cumulative indices for merged DMUs 


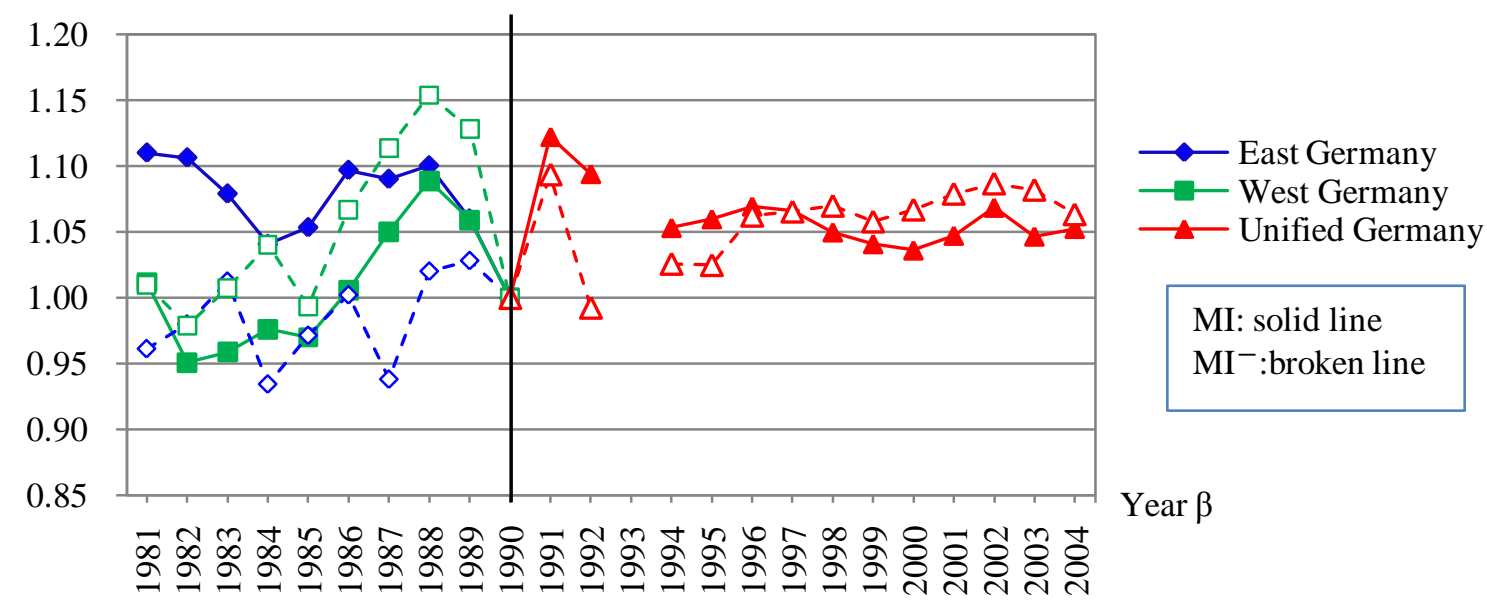

Fig. 8. $M I[1990, \beta]$ and $M I^{-}[1990, \beta]$ for East, West, and reunified Germany 


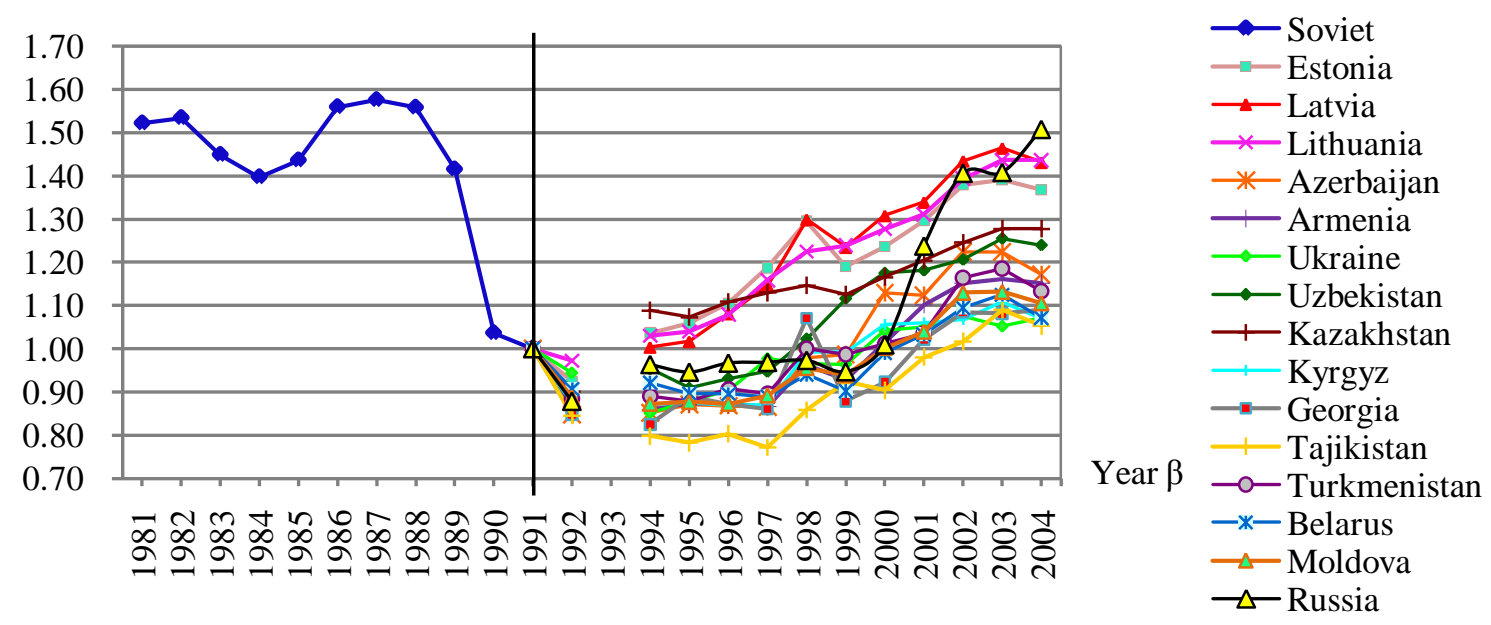

Fig. 9. Cumulative indices $M I[1991, \beta]$ for the former Soviet Union and its successor countries 


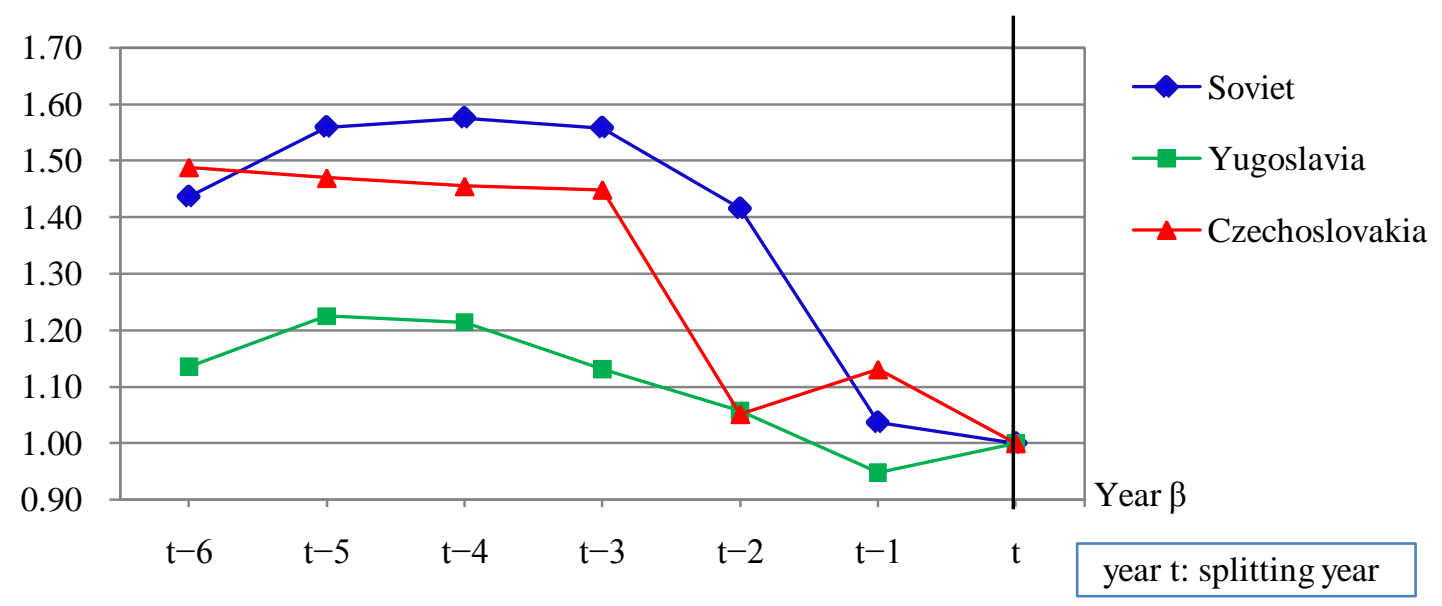

(a) Shifts of $M I[t, \beta]$ for Soviet Union, Yugoslavia, and Czechoslovakia

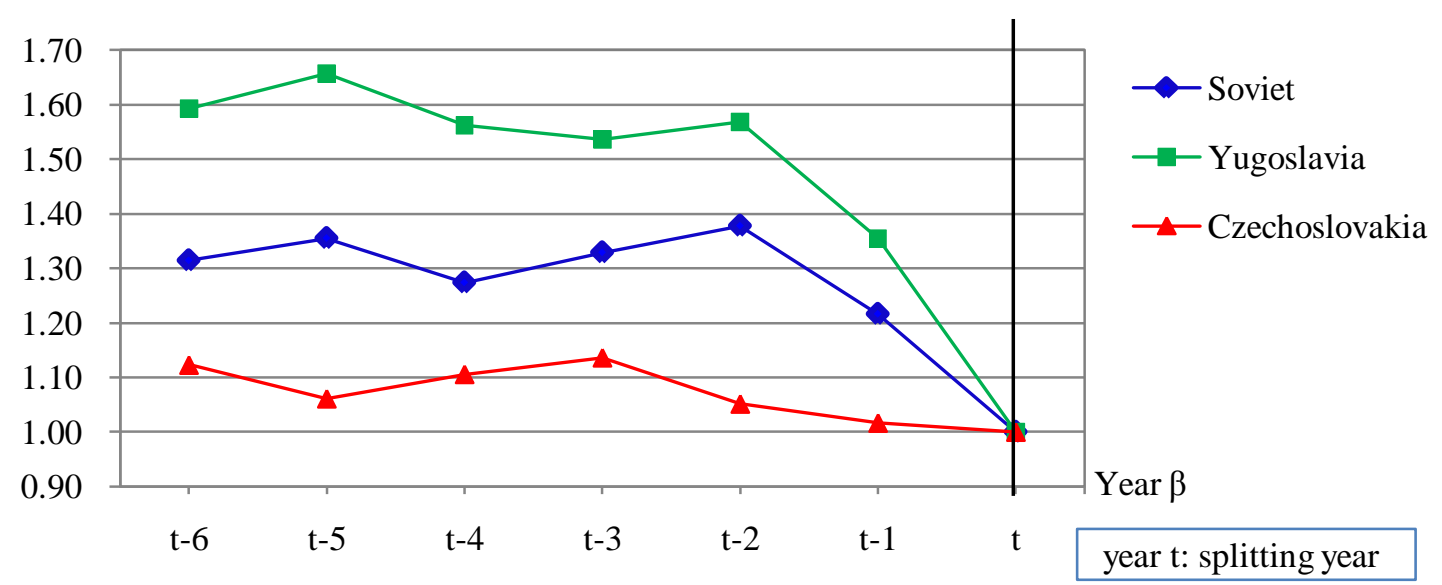

(b) Shifts of $M I^{-}[t, \beta]$ for Soviet Union, Yugoslavia, and Czechoslovakia

Fig. 10. Changes in nation stability leading up to a split 
Table 1

Typical phenomena in the four aspects of social and economic systems

\begin{tabular}{|c|c|c|}
\hline & internal & external \\
\hline economy & $\begin{array}{l}\text { - economic advance } \\
\cdot \text { infrastructure } \\
\cdot \text { money and banking system } \\
\cdot \text { national resources } \\
\cdot \text { geographical condition }\end{array}$ & $\begin{array}{l}\cdot \text { international trade } \\
\cdot \text { infrastructure } \\
\cdot \text { geographical condition }\end{array}$ \\
\hline society & $\begin{array}{l}\text { - political violence } \\
\text { - political freedom } \\
\text { - civil liberty } \\
\text { - crime } \\
\text { - terrorism } \\
\text { - law and order } \\
\text { - schools and education } \\
\text { - medical and health care }\end{array}$ & $\begin{array}{l}\text { - external aggression } \\
\text {-cross-border invasion } \\
\cdot \text { international crime } \\
\cdot \text { infectious disease }\end{array}$ \\
\hline
\end{tabular}


Table A.1

Set of 97 sample countries

\begin{tabular}{|c|c|c|c|}
\hline Region & Country & Region & Country \\
\hline \multirow{14}{*}{ Africa } & Algeria & USSR & Soviet Union $(-1991)$ \\
\hline & Egypt & & Estonia (1992-) \\
\hline & Tunisia & & Latvia (1992-) \\
\hline & Morocco & & Lithuania (1992-) \\
\hline & Libya & & Azerbaijan (1992-) \\
\hline & Ghana & & Armenia (1992-) \\
\hline & Nigeria & & Ukraine (1992-) \\
\hline & Gabon & & Uzbekistan (1992-) \\
\hline & Kenya & & Kazakhstan (1992-) \\
\hline & Tanzania & & Kyrgyz (1992-) \\
\hline & Zambia & & Georgia (1992-) \\
\hline & Zimbabwe & & Tajikistan (1992-) \\
\hline & South Africa & & Turkmenistan (1992-) \\
\hline & & & Belarus (1992-) \\
\hline \multirow[t]{23}{*}{ Asia } & North Korea & & Moldova (1992-) \\
\hline & South Korea & & Russia (1992-) \\
\hline & Taiwan & & \\
\hline & China & Europe & Ireland \\
\hline & Indonesia & & UK \\
\hline & Singapore & & Sweden \\
\hline & Thailand & & Denmark \\
\hline & Philippines & & Norway \\
\hline & Malaysia & & Finland \\
\hline & India & & Austria \\
\hline & Sri Lanka & & Netherlands \\
\hline & Pakistan & & Switzerland \\
\hline & Bangladesh & & Germany \\
\hline & $\mathrm{UAE}$ & & East Germany \\
\hline & Israel & & West Germany \\
\hline & Iraq & & France \\
\hline & Iran & & Belgium \\
\hline & Oman & & Italy \\
\hline & Kuwait & & Spain \\
\hline & Saudi Arabia & & Portugal \\
\hline & Turkey & & Greece \\
\hline & Bahrain & & Yugoslavia (-1991) \\
\hline & & & Slovenia (1992-) \\
\hline \multirow{4}{*}{$\begin{array}{l}\text { North } \\
\text { America }\end{array}$} & USA & & Croatia (1992-) \\
\hline & Canada & & Macedonia (1992-) \\
\hline & Mexico & & Bosnia and Herzegovina (1992-) \\
\hline & & & Serbia and Montenegro (1992-) \\
\hline \multirow{10}{*}{$\begin{array}{l}\text { South } \\
\text { America }\end{array}$} & Argentina & & Czechoslovakia (-1992) \\
\hline & Uruguay & & Slovakia (1993-) \\
\hline & Ecuador & & Czech (1993-) \\
\hline & Colombia & & Hungary \\
\hline & Chile & & Poland \\
\hline & Paraguay & & Romania \\
\hline & Brazil & & \\
\hline & Venezuela & Oceania & Australia \\
\hline & Peru & & New Zealand \\
\hline & Bolivia & & Papua New Guinea \\
\hline
\end{tabular}

